

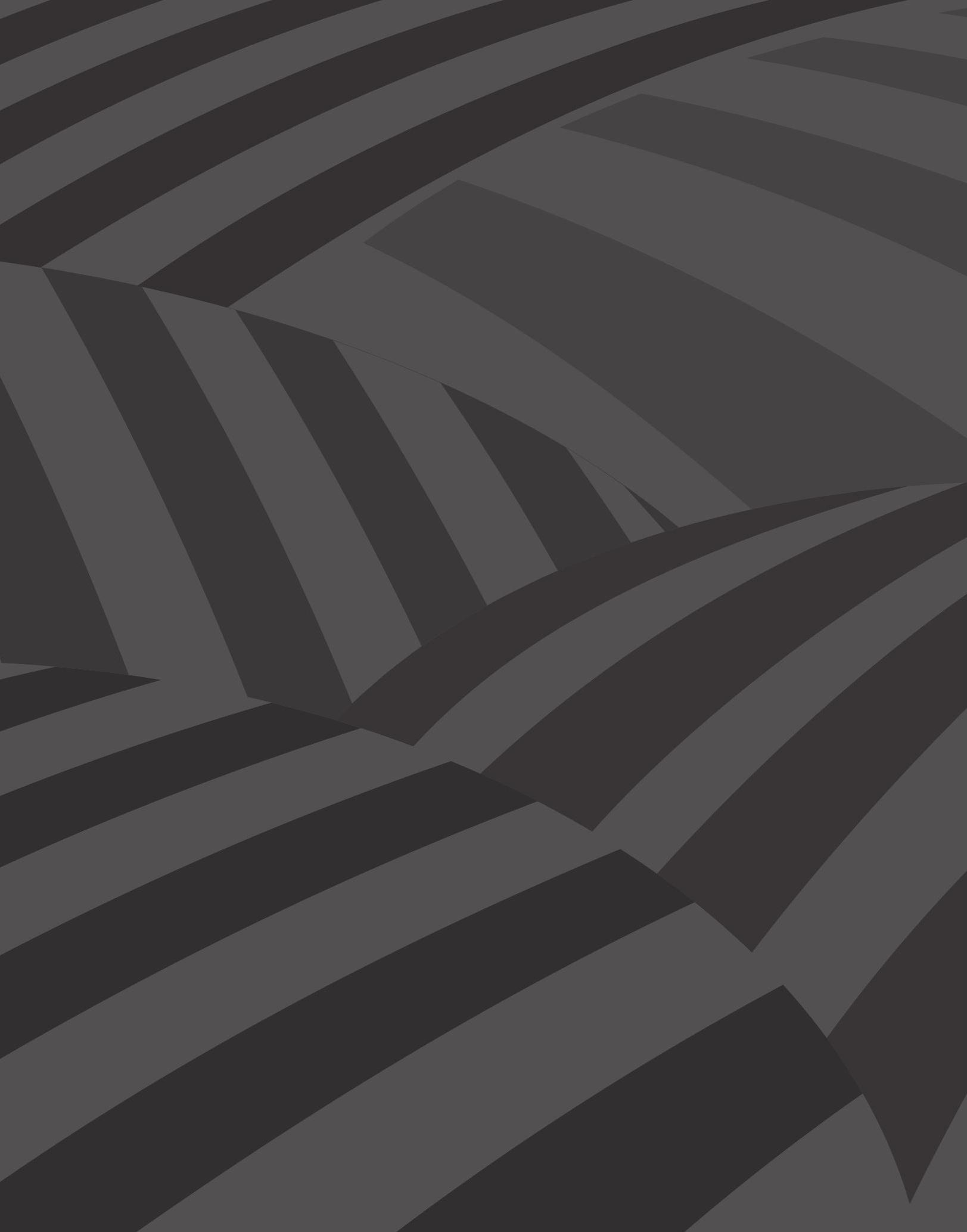




\title{
Pequeñas empresas y reacciones sociales ante la construcción de una autopista en el golfo de México
}

\author{
Por Saúl Horacio Moreno Andrade*
}

Resumen: Las micro y pequeñas empresas que se fueron estableciendo a orilla de carretera en un municipio del estado mexicano de Veracruz, ubicado en la costa del golfo de México, pusieron las condiciones objetivas para la activación de reacciones sociales ante la construcción de una autopista que une a las ciudades de Xalapa y Puerto de Veracruz. Las reacciones sociales —negociación, resistencia y aceptación - se debieron, en parte, a la amenaza a las economías locales que implicaba la reducción del flujo vehicular, pero también al impacto a un modo de vida. Aquí explicamos la importancia de que las decisiones públicas consideren los intereses de los ciudadanos ante los proyecto globales.

Palabras clave: decisión pública, reacciones sociales, economías locales, pequeñas empresas, construcción de autopistas

\section{Small Companies and Social Reactions to the Construction of a Highway in the Gulf of Mexico}

Abstract: The micro and small companies that were established at the edge of the road in a municipality of the Mexican state of Veracruz, located on the coast of the Gulf of Mexico, set the objective conditions for the activation of social reactions to the construction of a highway that unites the cities of Xalapa and Puerto de Veracruz. The social reactions (negotiation, resistance and acceptance) were due, in part, to the threat to local economies that implied the reduction of vehicular flow, but also to the impact on a way of life. Here we explain the importance of public decisions considering the interests of citizens before global projects.

Keywords: public decision, social reactions, local economies, small companies, highway construction.

Cómo citar este artículo: Moreno Andrade, Saúl Horacio (2020). Pequeñas empresas y reacciones sociales ante la construcción de una autopista en el golfo de México. Revista Controversia, 214, 243-277.

Fecha de recepción: 12 de septiembre de 2019

Fecha de aprobación: 2 de diciembre de 2019

* Profesor-investigador titular C del Centro de Investigaciones y Estudios Superiores en Antropología Social, Unidad Golfo. México. Correo electrónico: saulhoracio@ciesas.edu.mx 


\section{Introducción}

on muchas las impresiones que se pueden tener acerca de la globalización, pero es de gran utilidad analítica recuperar las versiones locales sobre la conformación de una nueva realidad socioespacial impuesta desde los centros de poder globales y que repercute profundamente en la relación entre micro y pequeñas empresas locales y la reconfiguración de los territorios. En este artículo se revisa el impacto de la decisión pública de carácter global, de abrir una autopista entre el Puerto de Veracruz y Xalapa, la capital del estado de Veracruz (México). Para la comprensión de dicho proceso se perfilan tipos de reacciones sociales a partir de sus efectos sobre micro y pequeñas empresas dentro del mencionado territorio, aunque también en el impacto sobre los modos de vida de las comunidades estudiadas.

Las decisiones de política pública dentro de un régimen autoritario, como ha sido el mexicano, no toman el sentir del público, aunque suene conceptualmente paradójico, y, por tanto, no consideran los efectos que pueden tener dichas políticas sobre los espacios locales donde la población desarrolla su vida cotidiana, su economía y sus relaciones sociales. En cambio, solamente se preocupan por los intereses de los particulares que invierten sus capitales en la realización de dichas obras. De esta manera las decisiones públicas han sido, enmascaradamente, decisiones de intereses privados con gran capacidad de inversión, que usan lo público para la generación de un muy alto beneficio particular. Pero existen otros actores privados muy pequeños: los micronegocios que se ven afectados por estas obras ${ }^{1}$. Los que tienen menor capacidad de inversión han sido aplastados por los grandes inversionistas nacio-

1 La Secretaría de Economía de México define a estos negocios así: "Las microempresas son todos aquellos negocios que tienen menos de 10 trabajadores, generan anualmente ventas hasta por 4 millones de pesos y representan el 95 por ciento del total de las empresas y el 40 por ciento del empleo en el país; además, producen el 15 por ciento del Producto Interno Bruto.” http://www.2006-2012.economia.gob. $\mathrm{mx} /$ mexico-emprende/empresas/microempresario. Consultada en agosto de 2017. 
nales y extranjeros. En el caso de Veracruz, estos intereses han sido una conjunción entre las redes de las élites políticas y empresariales en favor de estas últimas, sin considerar a los micros y pequeños negocios que son impulsados por actores locales. Esta es una situación común en sociedades que transitan de un Estado autoritario centralizado a un conjunto de reformas que buscan salidas democráticas (Báez-Camargo y Ledeneva, 2017). En México ha sido claramente señalado cómo la corrupción de las relaciones dentro del Estado y entre el Estado y la sociedad alcanza niveles que pasan de la informalidad a la criminalidad (Flores, 2017), siempre generando ganancias para las inversiones mayores a costa de aplastar a los menores y sus localidades.

En este marco, la construcción de libramientos, autopistas, pasos a desnivel y otras obras públicas surgieron con el argumento de que ahorrarán tiempo a los viajeros, aunque en aras de esa mejora de tiempo la decisión "pública” modificó las formas de vida y las economías que los habitantes han construido al lado de las carreteras a lo largo de décadas. En el caso de las carreteras del golfo de México, las poblaciones por donde pasan las vías terrestres de transporte establecieron negocios que, diversamente, han ofrecido servicios relativos a los vehículos — refacciones, mecánica, electricidad, reparación de llantas - y servicios relativos a los pasajeros y conductores — hospedaje, alimentación, servicios médicos, entretenimiento-. Estos servicios se proveen generalmente por parte de micros y pequeñas empresas. El trazo de las carreteras ha llegado a atravesar pueblos o ciudades completas, incluso ha generado el surgimiento de poblaciones al ser fuente de ingresos para los pobladores. Durante el trabajo de campo que sustentó este artículo, un empresario restaurantero comentó: "la carretera es como un río de dinero".

Este escrito es producto de un trabajo de campo del proyecto de investigación del Centro de Investigaciones y Estudios Superiores en Antropología Social (CIESAS), titulado "Dinámicas de impacto local por implementación de políticas públicas en la zona metropolitana de Xalapa, Veracruz”, adelantado durante varios meses en los años de 2016 y 2017 
en el municipio Emiliano Zapata, Veracruz. El texto está compuesto por cinco apartados. En el primero se hace una disquisición teórica entre el concepto de globalización, la metropolitización y el papel de las subjetividades en las reacciones sociales. En el segundo se presenta el área de estudio; el municipio mexicano Emiliano Zapata, en el estado de Veracruz. En el tercero se describe la autopista en cuestión y se muestra su valor histórico, económico y político para el país. En el cuarto apartado, a partir de un análisis de las reacciones sociales se hace una tipificación en tres formas predominantes: negociación, resistencia y aceptación. El último y quinto apartado ilustra las maneras en que tres comunidades de la autopista Veracruz-Xalapa reaccionaron a la imposición de los diversos tramos que la componen.

El propósito es representar las versiones de los actores entrevistados y la manera en que se viven los cambios en la relación de lo local con lo global, como aporte para seguir comprendiendo las formas de reacción de la sociedad mexicana ante las imposiciones que se le hacen desde el Estado y los gobiernos locales, con el fin de buscar nuevas formas de relación entre la sociedad y el Estado.

\section{Espacios e impacto local de la globalización}

No hay duda de que las decisiones públicas enmarcadas en los procesos de la globalización trastocan la configuración de los espacios de las localidades. De otra parte:

Los espacios toman sentido a partir del razonamiento instrumental del capital que organiza la vida social bajo los principios de eficacia, lucro y generación de valor. La producción capitalista a lo largo de la historia se ha valido de diversas innovaciones tecnológicas para acelerar el flujo de mercancías, personas, dinero y bienes. (Bueno y Pérez, 2006, p. 10).

En esta aceleración de los procesos, bajo una lógica de valorización de las mercancías, el transporte ocupa un lugar central. Las autopistas 
cumplen este cometido globalizador; por tanto, sus impactos sobre las localidades son un objeto de atención ineludible, "un desafío multidisciplinario" en el sentido de la introducción que hacen Carmen Bueno y Margarita Pérez en su libro Espacios globales (2003, pp. 9-19).

Con base en lo anterior, este escrito no puede encasillarse en una disciplina, pues es producto de un trabajo de campo etnográfico intenso, con el apoyo de la teoría social acerca de la regionalización y la globalización contemporánea. Esto implica compartir con Saskia Sassen su propuesta metodológica que dice:

Más que buscar un modelo, lo que se busca es una suerte de lupa que permita ver las partes de aquello que hemos llegado a considerar necesariamente como un todo, para así rastrear la formación de las capacidades que en efecto han "cambiado de rumbo", ya sea en el Medioevo, en la época de Bretton Woods o en la era global, es decir, las capacidades que se han reubicado en nuevos ensamblajes (2010, p. 32).

En cada formación social concreta las subjetividades en su articulación con el poder tienen un papel central en dichos cambios de capacidades. Frente a las transformaciones estructurales las subjetividades son aquellas capacidades que activan a la acción social, por tanto la participación activa de los sujetos en los cambios. Lo cual solo puede tener lugar por las condiciones históricas que permiten el surgimiento de las subjetividades. Así como se desarrollan etapas para explicar la historia del mundo, se pueden reconocer etapas en la historia de las localidades y en las formaciones sociales concretas donde los sujetos resuelven sus contradicciones a partir de una intersubjetividad que puede pasar por alianzas, rupturas, conflictos y, en casos extremos, llegar a la violencia. El argumento de Sassen es correcto: requerimos de lupas para poder comprender el sentido de las acciones sociales en la determinación de los territorios.

Siguiendo lo anterior desde una perspectiva crítica, el actual modelo de desarrollo que implica la sumisión a un solo pensamiento universal 
para el logro de la modernización social conllevaría la racionalización de los espacios, desde una única manera de saber: la del dinero. Un orden colonial impuesto desde sus orígenes por la espada de los conquistadores (Porto-Gonçalves, 2009). Condición que se conserva relativamente en la posición de gobernados y gobernantes en la actualidad, en especial con la coerción de los grandes proyectos de aceleración de los flujos capitalistas. Por eso la necesidad de incorporar las subjetividades en la explicación de estos procesos de sumisión y sujetación, para comprender la presencia del "trabajo vivo" como el lugar donde los actores dominados, o aún colonizados, pueden representarse a sí mismos en relación con la imposición de un proyecto donde nuevamente la capacidad cosificadora del dinero los objetiviza, incluso en la concepción de ciudadano/a. Por eso se requiere repensar la política como el espacio de realización de los sujetos en el reconocimiento de su poder ante las obligaciones no consensuadas. Saliéndose de la política se puede accionar el poder de las subjetividades. Y esto refiere necesariamente a la subjetivación de las espacialidades. Como señalan Chignola y Mezzadra:

Pero estos procesos son acompañados desde el inicio por prácticas de subjetivación, que se producen cuando la libertad excede los esquemas pensados para amarrarla y obliga al poder a reinvestirse en otra instancia, en otras tecnologías o en otros saberes, para recuperar productivamente el control sobre aquello que, siempre de nuevo, se escapa. La tensión entre sujeción y subjetivación se inscribe tanto en la dinámica y en los conceptos políticos fundamentales (de la soberanía a la ciudadanía) como en la relación de capital, marxianamente constituida por la escisión entre fuerza de trabajo y capital. Criterios esenciales de organización de las relaciones de dominio, como el género y la raza, operan sobre ambos terrenos para distribuir a los sujetos en posiciones asimétricas. Ellos mismos son, sin embargo, continuamente transformados en bases materiales de procesos de subjetivación (2015, p. 1). 
Estas nuevas formas de racionalización capitalista y de sometimiento de las subjetividades representan una relativa continuidad de la colonización para América Latina, como se mencionó líneas arriba, y han llevado a una metropolización fracturando la vieja dicotomía rural-urbano. Las grandes regiones metropolitanas tienden a constituirse en la forma central de la organización territorial del capitalismo flexible, donde se concentra crecientemente la información - como factor clave del nuevo régimen de acumulación- y, por tanto, de las decisiones, las inversiones y los denominados servicios avanzados (Cuervo, 2003, p. 18). Decisiones tomadas desde los grandes intereses centrales, quienes en el espacio sujetan a la fuerza de trabajo reorganizando el transporte de las mercancías y los bienes, siempre acordemente con las necesidades de los grandes inversores dominantes.

Para comprender el impacto de una autopista que liga dos zonas metropolitanas de México, Xalapa y Veracruz, se debe tomar en cuenta que tal proceso se da en un contexto de resistencia, cambio y reorganización sociopolítica que ha tenido resultados incómodos para las localidades afectadas, aunque de manera diferenciada. Así, como señala Cuervo (2003), el nuevo patrón de metropolización parece acentuar los fenómenos de exclusión social y fragmentación territorial, en función de un comportamiento sumamente selectivo en términos territoriales de inversión/desinversión por parte del sector público y privado.

En este diseño global los procesos de flujo son cada vez más importantes. Así como la información se obtiene a través del continumm de la comunicación en la autopista de la informática, de igual forma el desplazamiento constante de los bienes, servicios, objetos, personas y recursos materiales se tiene que dar en las autopistas y carreteras que se definen por la construcción de los entramados metropolitanos.

De acuerdo con esto existe un actor no humano central: el vehículo con motor de combustión interna de ruedas, que se ha impuesto como principal medio de transporte y es un instrumento, por el momento, irremplazable. 
Efectivamente, la práctica totalidad de los coches que se fabrican en el mundo están diseñados por y para occidentales: el número de asientos, la velocidad máxima, la capacidad de combustible, el tipo de combustible; todo está pensado para ser utilizados por familias de como máximo cinco miembros, para rodar por carreteras o autopistas con un firme liso y uniforme; para ser repostados en una red de estaciones de servicio, y para ser reparados en talleres especializados, capaces de entender el funcionamiento de los cada vez más sofisticados elementos que los integran (Sánchez, 2002, p. 69).

Dentro del proceso de movimiento globalizado, las vías de transporte son completamente insustituibles para el paso de los vehículos de combustión interna, ya que del concepto de auto se derivan camiones, tráileres, grúas y toda una serie de máquinas en las que el desplazamiento por tierra, por medio de ruedas impulsadas por un motor de combustión interna es su punto en común.

En esta dimensión globalista del transporte, las autopistas y carreteras se vuelven la base para enlazamiento territorial desde el desarrollo económico-empresarial, pero también desde la óptica del Estado y su necesidad de control policiaco-militar. Sin ellas no sería posible la articulación espacial derivada de la reorganización de las actividades comerciales, recreativas y políticas. "Podemos hablar así de nuevos objetos urbanos: shopping centers, hipermercados, parques de ocio y espectáculo, barrios privados, edificios inteligentes, accesos y autopistas metropolitanos, nuevas aglomeraciones industriales, etc.” (Cuervo, 2003, p. 18).

Los grandes avances se caen por los efectos sociales de las decisiones públicas. A diferencia de los dueños de los vehículos automotores, para el hombre de a pie, literalmente, estos procesos pueden convertirse en una pesadilla o en un alegre sueño según la posición en donde quede. Todas las innovaciones derivadas del transporte implican transformaciones en el espacio. El punto es que dentro del territorio está la población, y esta se compone de personas concretas que no están dispuestas a ver modificado su medio ambiente sin que se les consulte y sin tener 
una idea general del destino que les depara obras de gran magnitud, como la conversión de carreteras en autopistas.

Para el caso de las autopistas y carreteras, existen poblados y pobladores que se quedan en medio del proceso de cambio global. Dice un autor chileno: "El proceso de globalización pasa desde hace más de dos décadas por encima de América Latina, del mismo modo que pasa por encima del mundo: como un huracán” (Hinkelammert, 2001, p. 5). Esto ha ocurrido cuando pequeñas y medianas localidades se encuentran en el trazo de una vía de transporte, pues acaban siendo arrasadas por el huracán de los intereses globales, nacionales y transnacionales. Ese fue lo que ocurrió en aquellas poblaciones que se encontraban en medio de las dos más importantes zonas metropolitanas del estado de Veracruz: Xalapa y Veracruz, y que ejemplifican uno de los múltiples casos de implementación de decisiones públicas en las que el público no ha intervenido en su construcción.

\section{Emiliano Zapata, municipio de la zona metropolitana de Xalapa}

Este municipio lleva el nombre de uno de los próceres de la Revolución mexicana: Emiliano Zapata. Es parte de la zona metropolitana de Xalapa que comprende siete municipios del estado de Veracruz.

Antes de continuar, conviene mencionar que México es una República Federal conformada por treinta y dos estados y que cada uno está dividido en municipios con administraciones locales (ayuntamientos); por tanto, tiene tres niveles de gobierno: federal, estatal y municipal. México mantiene una división de tres poderes: el Poder Ejecutivo (Presidencia de la República), el Poder Legislativo (Cámara de Diputados y Cámara de Senadores) y el Poder Judicial (Suprema Corte de Justicia).

En el estado de Veracruz estos tres poderes se representan así: el Poder Ejecutivo en la figura del gobernador; el Poder Legislativo en una asam- 
blea denominada Congreso del estado, formado por cincuenta diputados, treinta electos por el principio de mayoría relativa y veinte electos por el principio de representación proporcional; y el Poder Judicial en cabeza del Tribunal Superior de Justicia.

Respecto a la división territorial, Veracruz está integrado por doscientos doce municipios agrupados territorialmente en ocho zonas metropolitanas: Acayucan, Poza Rica, Xalapa, Veracruz, Coatzacoalcos, Minatitlán, Orizaba y Córdoba. Con base en lo anterior, para comprender la posición estratégica del municipio de Emiliano Zapata se precisa decir que la zona metropolitana de Xalapa (ZM-Xalapa) está conformada por seis municipios más: Banderilla, con 19170 habitantes; Coatepec, con 79 787 habitantes; Jilotepec, con 13653 habitantes; Rafael Lucio, con 5966 habitantes; Tlalnelhuayocan, con 13855 habitantes y Xalapa, con 413 136. El municipio de Emiliano Zapata tiene 494764 habitantes. Los siete municipios sumaban en 2009 una población total de 595043 habitantes. ${ }^{2}$

La dinámica xalapeña impacta directamente en el municipio de Emiliano Zapata, el cual está vertebrado geográficamente por la autopista que une a Xalapa con la ciudad de Veracruz. ${ }^{3}$ Es una puerta de entrada y salida de mercancías, personas, comunicaciones y bienes de todo tipo desde el puerto de Veracruz a la zona del altiplano, donde está ubicada Ciudad de México.

2 De acuerdo con el Instituto Nacional de Estadística, Geografía e Informática (INEGI), el Consejo Nacional de Población (CONAPO) y la Secretaría de Desarrollo Social (SEDESOL).

3 Emiliano Zapata está rodeado al norte por los municipios de Xalapa y Actopan, al sur por Apazapan y Puente Nacional, y al oeste por Coatepec y Jalcomulco. Se viven temperaturas máximas de $30^{\circ} \mathrm{C}$, mínimas de $10^{\circ} \mathrm{C}$ y medias de $20^{\circ} \mathrm{C}$, lo que da tres climas en su territorio: (1) semicálido húmedo con lluvias de monzón, con un porcentaje de lluvia invernal mayor de 5 y precipitación en el mes más seco menor a $40 \mathrm{~mm}$; (2) cálido subhúmedo con lluvias en verano menor a 43.2 y un porcentaje de lluvia invernal de 5 de la anual; y (3) cálido subhúmedo intermedio con lluvias entre 43.2 y 55.3 y un porcentaje de lluvia de invierno menor a 5 de la anual. 
Para México, el valor histórico del puerto de Veracruz es imponderable. Fue el primer puerto marítimo, la puerta entre la Corona española y la Nueva España. Allí se formaron las primeras estructuras entre Gobierno y gobernados para la Nueva España. Es considerado cuatro veces heroico en la defensa de la soberanía ante los ejércitos europeos y de los Estados Unidos (Ortiz, 2010, p. 7). Es uno de los centros turísticos más importantes. En su estructura industrial destacan la empresa Tubos de Aceros de México (TENARIs-TAMSA) y la Administración Portuaria de Veracruz (APIVER). Para ilustrar esto último vale mencionar que,

Su ubicación continental lo ha favorecido, pues el 80 por ciento del total de carga que mueve, entra (mercancía exportada) o sale (bienes importados) al Distrito Federal y a los estados de México, Puebla, Tlaxcala y obviamente Veracruz, donde los cuatro primero mencionados, que constituyen su principal hinterland, forman una región que concentra a las entidades productivas, industriales y comerciales más importantes del País; también se mueven mercancías que tienen como origen o destino los estados de Guanajuato, Jalisco, San Luis Potosí, Hidalgo, Chiapas, Morelos, Oaxaca, Querétaro y Tabasco (Ortiz, 2010, p. 7).

Aunque al área interna de influencia del puerto de Veracruz es mayor, al hacer referencia a la zona del altiplano se habla de los estados comentados en la cita anterior. Desde el otro lado de la relación global, su foreland lo constituyen los puertos de Amberes, Bélgica; La Spezia, Italia; Barcelona, España; Le Havre, Francia; Barranquilla, Colombia; Miami, Estados Unidos; Bilbao, España; Nueva Orleáns, Estados Unidos; Bremen, Alemania; Puerto Cabello, Colombia; Bremerhaven, Alemania; Puerto Limón, Colombia; Buenos Aires, Argentina; Rótterdam, Holanda; Cartagena, Colombia; San Juan, Puerto Rico; Dublín, Irlanda; Santos, Brasil; Galveston, Estados Unidos; Thamesport, Inglaterra; Génova, Italia; Tampa, Estados Unidos; Houston, Estados Unidos; Valencia, España. (Ortiz, 2010, p. 8). 
Según datos del mismo autor:

El 59.70 por ciento del tráfico de mercancías por el puerto mexicano en estudio, corresponde a operaciones con Estados Unidos de Norteamérica, 19.54 por ciento con varios países de Europa, 13.55 por ciento con distintas naciones de América del Sur y el restante 7.21 por ciento son rutas que lo comunican con puertos localizados en Asia, África, América del Centro y el Caribe.

Es decir, la relación con los Estados Unidos de Norteamérica es intensa. Ese es el contexto que explica la importancia de una autopista entre el puerto de Veracruz y la ciudad Xalapa. Aunque hay otras rutas semejantes, es indudable que toda obra que se realice en el territorio que abarca la ruta del puerto de Veracruz hacia el altiplano de México - y que cubre Tlaxcala, Puebla, Ciudad de México, Estado de México- es de importancia estratégica. Por tanto, las localidades que se ubican en los municipios que atraviesa dicha ruta son afectadas por la constante actualización, de acuerdo a las necesidades nacionales, los recursos en cuestión y el estado de la tecnología de la carretera. Situación que no es novedosa, ya que la autopista Xalapa-puerto de Veracruz comenzó como un camino de caballos y carretas, siguió como vía del tren (Vázquez, 2017), continúo como carretera de dos carriles y actualmente es una autopista de cuatro carriles. Por lo mismo, la importancia de sus municipios proviene desde la época colonial del país ${ }^{4}$ y de lo que se llamó el Camino Real Veracruz-México (Muñoz Espejo, s.f.) ${ }^{5}$.

4 En este punto conviene aclarar que la ciudad de Veracruz, en donde se ubica el puerto de Veracruz, es parte de zona metropolitana conformada por los municipios de Veracruz, con 512310 habitantes; Boca del Río, con 141906 habitantes; Alvarado, con 48178 habitantes y Medellín, con 38840 habitantes. Esto da un total de 741234 personas. Es de imaginarse el flujo vehicular entre ambas ciudades y el constante intercambio de bienes, servicios, comunicaciones y personas. Es indudable la necesidad de una vía de acceso rápida, segura y eficiente entre las dos ciudades más importantes del Estado de Veracruz.

5 https://www.cultura.gob.mx/turismocultural/cuadernos/pdf15/articulo13.pdf Consultada en abril de 2018 
Dentro de la zona metropolitana de Xalapa, el municipio de Emiliano Zapata contiene 124 localidades. Como es de notarse, el municipio y las localidades quedaron enmarcados dentro de la lógica de los tramos entre Xalapa y Veracruz. Por tanto, durante el proceso de construcción de la autopista las reacciones de las localidades ante lo que experimentaban como una imposición fueron diversas: aquellas que visualizaron que la llegada de la autopista las beneficiaría al convertirse en un polo de atracción para el consumo de alimentos de la clase media de Xalapa durante los fines de semana se mostraron a favor, las que no vieron las mismas posibilidades la vivieron como una catástrofe para su economía y su modo de vida, y aquellas que no dependían económicamente de su posición en la carretera centraron sus reclamos en reivindicaciones menos comerciales.

\section{La autopista Xalapa-Veracruz}

Según la Secretaría de Comunicaciones y Transportes (SCT) la autopista tiene una longitud de 101,568 kms y se divide en seis tramos. En realidad son siete tramos, ya que no toman en cuenta el libramiento de la localidad de Rinconada, tal vez por considerarlo continuación de la autopista y no como un tramo cuyo objetivo es librar el paso por dicho poblado. Agregando el libramiento de Rinconada, la autopista queda como en el Cuadro 1, donde se parte de Veracruz a la ciudad de Xalapa.

\section{Cuadro 1. Autopista Xalapa-Veracruz}

\begin{tabular}{|c|l|c|l|l|}
\hline No & \multicolumn{1}{|c|}{ Tramo } & $\begin{array}{c}\text { Distancia } \\
\text { en kms }\end{array}$ & $\begin{array}{c}\text { Caseta } \\
\text { de peaje }\end{array}$ & $\begin{array}{l}\text { Costo en pesos } \\
\text { (4 de enero de 2018) }\end{array}$ \\
\hline $\mathbf{1}$ & Veracruz-Entronque Veracruz & 07.090 & Sin caseta & 00.00 \\
\hline $\mathbf{2}$ & Entronque Veracruz-José Cardel & 29.880 & La Antigua & $\begin{array}{l}59.00 \text { (cincuenta } \\
\text { ynueve pesos } \\
\text { mexicanos) }\end{array}$ \\
\hline $\mathbf{3}$ & José Cardel-libramiento Rinconada & 13.000 & Sin caseta & 00.00 \\
\hline $\mathbf{4}$ & Libramiento de Rinconada & 05.610 & Sin caseta & 00.00 \\
\hline
\end{tabular}




\begin{tabular}{|c|l|c|l|l|}
\hline $\mathbf{5}$ & $\begin{array}{l}\text { Entronque Rinconada-entronque } \\
\text { Plan del Río }\end{array}$ & 09.390 & Sin caseta & 00.00 \\
\hline $\mathbf{6}$ & Libramiento Plan del Río & 12.000 & Plan de Río & $\begin{array}{l}45.00 \text { (cuarenta y } \\
\text { cinco pesos) }\end{array}$ \\
\hline 7 & Entronque Cerro Gordo-Xalapa & 24.598 & Sin caseta & 00.00 \\
\hline Total & Autopista Veracruz-Xalapa & 101.568 & Dos casetas & $\begin{array}{l}\$ 104.00 \text { (noventa y } \\
\text { dos pesos) }\end{array}$ \\
\hline
\end{tabular}

Fuente. Moreno (2016, p.207).

Respecto al desarrollo de la obra, en 2004 el entonces gobernador constitucional del estado de Veracruz, Miguel Alemán Velasco, señalaba en el 6to Informe de Gobierno 2003-2004 lo siguiente: "Este año entregamos a los veracruzanos, la autopista de altas especificaciones que une a Xalapa con la ciudad y puerto de Veracruz, misma que reduce el tiempo de traslado e incrementa la seguridad de los usuarios” (2004, p. XIX).

En el mismo documento, más adelante, Alemán Velasco afirma:

Para agilizar el tráfico en los puntos de contacto entre el tránsito de largo itinerario el local, se incorporaron 6 nuevos libramientos al sistema carretero estatal: Libramiento Plan del Río; Rinconada; Sur Martínez de la Torres; Chichicaxtle; Paso del Macho; y se inició, en una longitud de 1.2 kilómetros, el libramiento Las Puentes-San Marcos (2004, p.520).

El gobernador destaca la importancia de los libramientos para agilizar el flujo vehicular y evitar coaliciones y accidentes que afecten a la población de las localidades. Esta dinámica de los tramos de carretera hace que las autopistas sean fracciones que se van engarzando, dándole un sentido a la posibilidad de hacer en menos tiempo una mayor distancia. Esta necesidad de fluidez implica que los polos que definen la línea del camino sean las zonas metropolitanas antes que las localidades intermedias. Estas últimas se deben evitar lo más posible para lograr el cometido de la autopista: mayor distancia en menor tiempo. 
Sin embargo, el libramiento de Plan del Río tiene ubicada una caseta de peaje, lo que invita a que los conductores prefieran irse por la carretera libre a Veracruz y consumir alimentos en la localidad de Cerro Gordo, también ubicada en Emiliano Zapata; a diferencia, el libramiento de Rinconada no tiene caseta alguna, pero sí evita pasar por la localidad. En una nota de AvC Noticias, a diez años de la construcción del Libramiento se señaló:

El libramiento de Rinconada afectó la economía de los lugareños y principalmente a las familias que se dedicaban a la venta de garnachas, un platillo que identifica a esta región y que consiste en tortilla con salsa y carne. De los 104 puestos que había hasta 2004, actualmente quedan 34, explicó la agente municipal, María del Carmen Hernández Díaz, quien hizo la invitación para la feria de la garnacha que se realizará del 12 al 16 de septiembre. Consideró que este giro comercial cayó en promedio 70 por ciento, en los últimos diez años cuando comenzó el funcionamiento de la vía que dividió prácticamente a la congregación del paso de turistas. "Nosotros vivimos de la economía de la garnacha pues toda la gente que hace las tortillas, los campesinos que sembraban el maíz y todo eso se derrumbó por eso estamos tratando de levantarnos", explicó la agente municipal (2015, s/p).

En sentido contrario, las declaraciones del secretario de Comunicaciones del gobierno, ingeniero Gustavo Nachón Aguirre, afirmaba que la obra carretera del libramiento de Rinconada, era parte de lo que convirtió a Veracruz en la entidad federativa mejor comunicada: una de las obras más importantes de la administración de Miguel Alemán Velasco.

Acompañado de sus colaboradores, el secretario Gustavo Nachón Aguirre resumió los aspectos más relevantes que en el sector se realizaron durante el periodo 2002-2003. En la carretera de altas especificaciones Xalapa-Veracruz, entró en operaciones el libramiento Rinconada, con una longitud de 130.0 kilómetros, una de las obras más importantes de esta administración (Orizaba en Red, 2004, s/p). 
Entre las críticas de la prensa que alertaban sobre el daño a las micro y pequeñas empresas locales y la defensa del avasallamiento de la relación entre la gran empresa constructora y gobierno del estado de Veracruz, se presentaron diversas reacciones de dos actores locales: los ciudadanos y los empresarios locales. En algunos casos la implementación de la política pública generó nuevas pequeñas empresas, particularmente de alimentos preparados, pero en otros destrozó las economías basadas en los micronegocios.

\section{Las reacciones locales en el municipio de Emiliano Zapata}

La construcción de la autopista Xalapa-Puerto de Veracruz y sus libramientos fue una decisión de política pública de orientación global: enlace resto del mundo-golfo de México-altiplano. La necesidad de incrementar la velocidad en el desplazamiento de vehículos por razones de comercio, turismo, movilidad de personas, bienes y servicios se sintetiza en ser un flujo de dinero. Como parte de una estrategia para acortar distancias y tiempos en el marco del orden global y efectuar una metropolización de espacios antes desconectados, las localidades quedan fuera de este intenso movimiento económico. El surgimiento de áreas de oportunidad para la inversión a gran escala —bodegas, oficinas, escuelas, gasolineras, diversos servicios carreteros (mecánicos, vulcanizadoras, refaccionarias), cantinas, restaurantes- deja a las poblaciones que en una carretera de dos carriles podrían participar activamente, sin lugar y fuera de la posibilidad de beneficiarse de la gran obra.

Esto se agrava más aún cuando las localidades, además de expulsadas del flujo económico, son aplastadas por la fuerza de las máquinas de construcción. De esta suerte, no se trata solamente de una reconversión de las economías locales, sino de una imposición política, un acto autoritario, dentro del cual los ciudadanos quedan sin capacidad de elegir entre más de una opción, como ocurrió con el proyecto de construcción 
de la autopista en mención. Es decir, la decisión pública —porque afectó al público- no contó con la participación de los principales afectados con su implementación: los ciudadanos. Entendiendo participación ciudadana, de manera amplia, como "el derecho de grupos y personas a incidir en el espacio público tanto estatal como no-estatal y es un ingrediente fundamental para la innovación y el fortalecimiento democrático y la construcción de gobernanza” (Hevia y Vergara-Lope, 2011, p. 10) y la imposición política como lo contrario a la falta de gobernanza, o sea, la falta de consideración por parte del poder estatal de la ciudadanía interesada y al público en general acerca de una obra pública.

Esta ausencia de gobernanza en la decisión de la construcción de la autopista Xalapa-Puerto de Veracruz llevó a que se conjugaran formas reactivas que surgieron como una configuración de subjetividades ante la "modernización impuesta”. Esta configuración de subjetividades impulsó la movilización ante la imposición del proyecto. Esta afirmación parte de que

la configuración subjetiva sería el arreglo o red específica de códigos provenientes de los campos de la cognición, valorativos, sentimentales, expresados o no discursivamente, y combinados en parte en forma pseudoinferencial, a través de categorías del razonamiento cotidiano. La configuración subjetiva da sentido a la situación concreta (en tanto explicar, decidir) relacionada con las prácticas. (De la Garza, 2018, pp. 194-195).

Las configuraciones que surgen del sentimiento de imposición a las localidades activaron códigos, algunos muy profundos (tradicionales) y otros novedosos (modernizantes), que generaron el razonamiento de que a la imposición de la autopista y a algunos libramientos en específico se les debía combatir, no por la obra en sí, sino por las formas autoritarias que cobijaron la decisión.

Hubo, al menos, tres tipos de reacciones sociales en las localidades: negociación, resistencia y aceptación pasiva. Aunque los tres tipos aparecían a la vez, hubo uno de ellos que prevaleció de acuerdo al contexto 
y a las relaciones sociales internas de cada comunidad, convirtiéndose en la corriente principal de razonamiento y argumentación en cada situación. De esta manera, cada tipo de reacción social fue una configuración subjetiva ante la imposición, donde entraron en acción los valores, los sentimientos, las apreciaciones estéticas, los temores, los razonamientos cotidianos entremezclados con razonamientos técnicos y posicionamientos políticos.

\section{Negociación judicializada}

Las localidades comprenden el proyecto, entienden que es una decisión tomada desde "las alturas", pero no lo ubican como amenaza en sí mismo, aunque sí el procedimiento. La acción gubernamental generó una acción colectiva, aunque se mueve una organización con base en el respeto de los pactos. Es una perspectiva de una cultura política que acepta relativamente la imposición de la obra y privilegia la lucha por la legalidad antes que la vía de presionar políticamente. Se accede a las formas tradicionales de organización social en donde se configuran subjetividades de orden político (respeto a las instituciones) e incluso de orden religioso (respeto a la autoridad).

\section{Resistencia politizada}

Implica una oposición frontal al proyecto que pretende reestructurar el espacio. Es importante comprender esta modernización forzada como un proceso negativo que alterará la forma de vida de los habitantes de un territorio, sin darles oportunidad de proponer alternativas ante el cambio, lo que implica un profundo sentimiento de imposición que lleva al rechazo de la reconfiguración espacial. De allí que sea una reacción social de choque ante la puesta en marcha de los trabajos carreteros. Se apela, como recurso privilegiado, la pugna política y los recursos entrelazados al sistema de partidos (relaciones, influencias, redes de poder) y al asambleísmo, el concepto de "pueblo" se vuelve central. 


\section{Aceptación negociada}

Se comprende la obra como parte de los procesos de cambio: se "sigue el flujo". Se ubican las áreas de oportunidad para crecimiento local apelando a la lógica económica del cambio. Los productos tradicionales se consideran la potencia de ubicación ante el cambio impuesto, pero como mercancías a colocar en la nueva situación. Se reconoce la imperatividad de la obra, pero se piensa que "así son las cosas" y que la pasividad y adaptabilidad traerá más beneficios que la resistencia y la confrontación.

\section{Casos ilustrativos de las reacciones sociales}

A continuación se presentan tres casos de localidades del municipio Emiliano Zapata, cada una con su correspondiente forma de reacción social.

\section{La negociación judicializada en la localidad de Corral Falso}

Esta localidad se ubica actualmente en el entronque de la autopista Xalapa-Cardel y el libramiento de Xalapa, en los kilómetros 17 y 18. Sus habitantes no se sustentan económicamente en los negocios pequeños y micros, pues en realidad viven de emplearse en la ciudad de Xalapa. Ellos experimentaron el 18 de mayo de 2001 la entrada de la maquinaria que iba a trabajar en la obra sin previo aviso, lo que les provocó confusión y miedo ante lo que estaba pasando. Los trabajadores de la constructora destruyeron la casa de una anciana, rompieron la tubería de agua potable y por una mala maniobra de la maquinaria se cayó un transformador de luz que dejó sin energía eléctrica a la localidad. Pasado el impacto, la comunidad respondió a dicha situación de diversas manera: primero conformaron un comité que se basó en la vieja organización campesina ligada a la Confederación Nacional Campesina y a las formas comunitarias del ejido mexicano.

Adicionalmente, los pobladores se organizaron para detener sistemáticamente la maquinaria que iba a trabajar en el libramiento hasta que fueran atendidos. En la búsqueda de apoyos el Comité se vinculó con 
la Comisión para la Defensa de los Derechos Humanos AC (CDDHAC), la más antigua organización civil defensora de estos derechos en la región. Antes de establecer su relación con la CDDHAC el comité visitaba las oficinas de la Secretaría de Comunicaciones y Transporte del Gobierno de Veracruz pero no eran atendidos. Los dejaban esperando en una oficina mientras el responsable se retiraba. Esta crisis aclaró situaciones que pudieron ser compuestas para las reposiciones de daños que hizo el Gobierno. Por ejemplo, algunas personas no contaban con documentos para acreditarse como propietarios de algunos terrenos, sino como concesionarios. Esto se fue resolviendo gracias a esta situación que puso en jaque la normalidad de la localidad.

Finalmente, con una negociación apoyada por la CDDHAC, el comité logró su objetivo: que el proyecto de construcción de la autopista se llevara a cabo respetando los acuerdos con la comunidad de Corral Falso, acuerdos que comprendían aspectos estructurales como el puente peatonal bien ubicado, los pasos ganaderos con desahogos de agua de lluvia, la reubicación de casas, la renovación de los ductos de agua y la acreditación de las propiedades.

Los habitantes reivindicaron como un triunfo el que sus derechos se respetaran y el haber podido ejercer una resistencia ante la imposición de la obra, basados en la defensa por la vía jurídica y en el principio religioso de "no somos políticos", aspecto muy importante ya que hay una comunidad amplia de Testigos de Jehová en Corral Falso.

Es importante señalar que esta solidaridad entre los habitantes de Corral Falso tuvo contradicciones de carácter político-religioso. La localidad se fracturó entre un liderazgo femenino que abogaba por la necesidad de apoyarse jurídicamente en la CDDHAC y un liderazgo masculino con menor presencia entre los Testigos de Jehová, que simpatizaba con el Partido Revolucionario Institucional (PRI) gobernante en Veracruz. En virtud de que la mayoría de la población no tenía interés en ser relacionada con un partido político, sino en mantenerse alejada lo más 
posible de las vicisitudes de dicho campo, las propuestas del liderazgo femenino tenían mayor impacto.

Decía la entonces líder de la localidad de Cerro Gordo, ante el problema de la imposición de la autopista:

Lo que pasa es que al principio estábamos unidos ¿no? Empezaron a mezclarse los políticos, diputados, (...) unos entonces se fueron cargando mucho a lo político y nosotros estábamos enfocados a lo que queríamos, no a la política, esto fue que se haya perdido el foco de lo que se quería, y fue como luchamos de manera individual, algunos se fueron a trabajar a gobierno, el (...) se fue a trabajar al palacio municipal, ya no había confianza, y entonces empezamos a luchar de manera más separada, como Corral Falso, y nadie se va a ir a trabajar a gobierno, una de las estrategias de gobierno era ofrecer un puestito y sacarlo de movimiento.

Afortunadamente para la localidad, las vicisitudes no lograron fracturarla completamente y se conservaron unidos en sus objetivos de enfrentar el poder de la Secretaría de Comunicaciones y Transportes del Gobierno del estado de Veracruz.

\section{La resistencia politizada en la localidad de Rinconada}

Ubicado en el Km 44 se encuentra el libramiento de Rinconada que pasa junto a la localidad del mismo nombre. Las micros y pequeñas empresas estructuraban la vida económica de este asentamiento que había basado sus ingresos en el consumo de los viajeros: por un lado, la clase media de la capital xalapeña y, por otro, los choferes de vehículos de motores pesados (camiones y tráileres) que transportan las mercancías del puerto de Veracruz a la zona del altiplano y viceversa. Una buena parte de estas actividades comerciales satisfacían las necesidades de los traileros: comida, higiene, diversión, relaciones sexuales o sentimentales, hospedaje, entre otros. Originalmente fue una localidad productora de papaya, fríjol, maíz, chile, tomate, guanábana, anona, limón, naranja, lima, frutillo, zapote, tamarindo, mango, palma de coco, granada, 
guayaba y ciruela, pero desde 1966, año en que se inauguró la carretera de dos carriles, las actividades comerciales y los micronegocios fueron ocupando un lugar central, además de transfigurar al poblado.

Rinconada se atribuye la creación de la garnacha, una tortilla con salsa de tomate y carne de pollo o res. Sus pobladores consideran que tienen "reconocimiento mundial" por este platillo que generó especificidades de trabajo femenino en cadena y una red de proveedores y comerciantes. Desde los años 60 la garnacha se convirtió en el atractivo principal de la localidad por su intenso sabor, por que atrajo a muchos visitantes y porque gracias a ella comenzó una etapa de prosperidad. Treinta años más tarde, en 1993, para el Carnaval de la Garnacha existían 104 puestos de garnachas y 92 restaurantes de antojitos ${ }^{6}$ en un tramo aproximado de 1 kilómetro de la calle principal del poblado; en 2018 aproximadamente quedaban 27 establecimientos. El efecto principal de la construcción imperativa del libramiento de Rinconada fue que los viajeros dejaron de detenerse a comer o a buscar algunos de los servicios de carretera que prestaba la localidad, incluso la gasolinera cerró, lo cual generó un daño grave a la estructura económica local que, como vimos, estaba basada en esta red de microempresas y en relaciones de confianza entre proveedores, trabajadoras y propietarios de los establecimientos.

Una de las principales personalidades de la localidad, a punto de alcanzar los cien años de edad, señala sobre la dependencia de la localidad con la carretera:

Era yo creo que agente municipal, Fui tres veces agente municipal y dos veces de la junta de mejoras tesorero y presidente. Parece que era yo agente municipal y dijeron solo que queremos una ampliación de 30 metros y dije: ¿Cómo? ¿Tumbar nuestro caserío? La carretera eran seis metros, ahí estába-

6 Frituras de maíz con queso o frijoles, así como una variedad de salsas picantes de sabores intensos y agridulces en algunos casos. En su preparación se usa manteca de cerdo para freír. 
mos, ahorita ve el boulevard, nosotros ahí teníamos nuestro negocio, seis metros eran de carretera, si ajustan a los treinta metros. Nosotros de este lado, del lado derecho, Veracruz-Xalapa, les vamos a ceder quince metros. Los negocios estaban pegados a los seis metros de carretera, entonces, este, nos pusimos de acuerdo porque los restaurantes estaban de este lado y allá eran tiendas, almacenes, eran los de los billetes. Los del lado derecho Xalapa-Veracruz decían que su casa valían mucho, bueno, problemones duros y pues platicamos con ellos, miren se les va a tumbar sus casas, todo lo que se quite (puertas, material) se les va a dar a ustedes, entonces cada quien va a ceder. Dijeron van a ceder 10 metros y ustedes los 15. A lo que dijeron los de aquel lado "nosotros no cedemos más que 5 metros y si no nos pagan nuestras casas, no - dijeron- sino venimos a comprar casas, venimos a ponerles que se va a ayudar y eso. Y dijeron: bueno, qué hacemos, serían 25 metros muy buenos ¿no?. De esa forma quedo, se inauguró en 1966 y dijeron pues bueno, aquí va a pasar la pista, después vino el problema con el libramiento. Dijeron: aquí Rinconada tiene topes, tiene ferrocarril, bueno cuatro o cinco defectos que no les aprecio a los de allá de la autopista nueva, bueno ultimadamente hagan lo que quieran y si se fueron para allá, y si unos tres meses no más nos veíamos unos a los otros, todo mundo se iba.

En 2001 cuando comenzaron las obras, los habitantes de Rinconada sabían lo que estaba pasando debido a que algunos de ellos eran expertos trabajadores en la construcción de carreteras y habían sido empleados por las compañías constructoras del país. Por eso comenzó una oposición feroz a la obra, detuvieron los trabajos y buscaron formas de organización ante el embate de la decisión gubernamental. La red de negocios que sostenía la localidad había estado conducida por las mujeres, se trata de negocios con mando femenino, pues los varones se ocupaban del trabajo del campo o de la construcción de carreteras

La resistencia comenzó con la formación del Comité Popular, conducido por representantes sociales como el presidente de la Asamblea Ejidal, quien en ese momento estaba militando dentro de un partido de oposi- 
ción de izquierda: el Partido de la Revolución Democrática (PRD). Ante esta situación, otros pobladores se organizaron formando un Comité Oficial, que según comentan tenía el apoyo del PRI, en ese momento gobernante en el municipio. Como otra parte de los pequeños empresarios estaban ligados al Partido Acción Nacional (PAN) de derecha, pronto la confrontación ante el gobierno pasó a ser una querella entre las partes del Comité Popular divido entre posiciones ideológicas irreconciliables. Politizada la escena de resistencia política al proyecto de autopista, el gobierno estatal dividió al Comité Popular y benefició al Comité Oficial. Así, la sociedad civil local se vio envuelta en una pugna que tenía como mira las elecciones del 2004 para la Alcaldía del municipio de Emiliano Zapata, cuyos resultados se presentan en el Cuadro 2.

\section{Cuadro 2. Resultados electorales en el municipio de Emiliano Zapata: 1997-2004}

\begin{tabular}{|l|c|c|c|c|c|c|c|c|c|c|c|}
\hline Año & PAN & PRI & PRD & $\begin{array}{c}\text { PRD-PT- } \\
\text { Conver- } \\
\text { gencia }\end{array}$ & $\begin{array}{c}\text { PRI- } \\
\text { PVEM }\end{array}$ & PT & PVEM & Otros & $\begin{array}{c}\text { Votos } \\
\text { Validos }\end{array}$ & $\begin{array}{c}\text { Votos } \\
\text { Nulos }\end{array}$ & Total \\
\hline $\mathbf{1 9 9 7}$ & 1,141 & 7,026 & 4,569 & & & 620 & 169 & 349 & 13,874 & 246 & 14,120 \\
\hline $\mathbf{2 0 0 0}$ & 2,562 & 4,602 & 2,976 & & & 601 & 240 & 3,557 & 18,781 & 792 & 19,573 \\
\hline $\mathbf{2 0 0 4}$ & 5,617 & & & 5,415 & 4,235 & & & 3,514 & 14,569 & 276 & 14,845 \\
\hline
\end{tabular}

Fuente. Moreno (2017, p.50).

En pocas palabras, el triunfo del PAN fue la evidencia de que la división política del Comité Popular le fue favorable. El Comité Oficial se desvaneció, el PRI perdió el control del municipio y ya no lo volvió a recuperar, pues después pasó a manos del $\mathrm{PRD}^{7}$ y actualmente gobierna el Movimiento de Regeneración Nacional (MORENA), partido de Andrés Manuel López Obrador.

7 Competían otros partidos como el Partido del Trabajo (PT), de izquierda; el Partido Verde Ecologista de México, de centro derecha; y Convergencia, de centro izquierda, pero eran partidos con menor presencia nacional que casi siempre habían participado en alianza con los partidos más grandes: PAN, PRI y PRD. 
Los impactos para la localidad fueron muy perjudiciales para su economía, como señala uno de los actores políticos de la época:

Hay una cuestión muy significativa que hubiera pegado menos el golpe económico, si la caseta que está postrada en la bocana la hubieran puesto aquí. Esta paralela a la bocana la hubieran instalado aquí hubiera mejorado, porque entonces la gente hubiera visto la forma de no pagar la caseta, para evitar el pago hubieran entrado a la comunidad. Ese detalle lo pasaron de alto (...) de ese modo Cerro Gordo de la nada, porque tú ves el mapa y ahora Palo Gacho tiene todo, el mejoramiento económico por los negocios, y todo aumenta sus costos, y aquí todo lo contrario.

Para colmo, la crisis económica de Rinconada se aparejó, como en el resto del país, con la crisis de seguridad pública. Para los primeros años del sexenio del expresidente Enrique Peña Nieto, como consecuencia del aislamiento que generó el libramiento de Rinconada, Veracruz convirtió al lugar en una cueva de bandidos y la ciudadanía tuvo que enfrentar una etapa de terror ante la inseguridad: secuestros, extorsiones y asesinatos se vivieron tanto en la localidad como en la región (Zavaleta, 2018). Esos tiempos difíciles han pasado, pero el desprestigio de Rinconada al ser visto como un lugar peligroso hizo que su aislamiento aumentara. Esfuerzos de las autoridades locales (agencia municipal en manos de una ciudadana) junto con la sociedad civil (Comisión de Festejos) lograron que se instaurará anualmente la Feria de la Garnacha con el fin de recuperar la confianza de sus clientes, quienes evitan pasar por el pueblo, bien por la comodidad y rapidez del libramiento, bien por el temor a ser víctimas de algún robo o asalto en las inmediaciones, aunque esto no es tan frecuente como en el pasado. La Feria de la Garnacha ha tenido un efecto positivo más de catorce años después de que el libramiento comenzará a funcionar, pero los habitantes aún culpan al gobierno estatal de aquellos tiempos, puesto que la dinámica microempresarial no se ha recuperado, aunque la esperanza sigue. 


\section{La aceptación negociada en la localidad de Cerro Gordo}

Ubicada en el entronque Cerro Gordo, Km. 24, es una exitosa zona de comercios y venta de alimentos a los viajeros. El modelo de empresa dominante es la cocina regional, con un servicio basado en valores cristianos: "Dar de comer al hambriento", el valor de la templanza, así como la resistencia a los placeres del mundo. A diferencia de Corral Falso, donde sus habitantes también se declaran religiosos, pero son empleados en la ciudad de Xalapa, los habitantes de Cerro Gordo son religiosos, pero aprovecharon la caseta de peaje ubicada en su libramiento y establecieron micronegocios de venta de frutas, bebidas refrescantes, dulces y artesanías. Destaca entre ellos un restaurante muy grande que ofrece antojitos y carnes asadas. ${ }^{8}$ La diferencia es que, mientras que en Rinconada las frituras prevalecen, en Cerro Gordo la oferta es lo asado al comal, buscando "sacar la cocina de mamá al cliente".

El restaurante en mención ha definido en buena medida las normas de éxito local: honradez, calidad y servicio, además de un estilo flexible de atención al cliente. Incluso, pensando en que alguien no tenga dinero para pagar los alimentos, creó una regla especial: la primera vez se le permite pedir al cliente a gusto y no cobrarle, la segunda ocasión que el cliente no tenga dinero se le puede dar de comer el platillo más barato.

Se mantiene el concepto de que al estar a orilla de carretera están sobre un río de dinero que fluye desde la capital. Dice el dueño del local señalado: “Xalapa es una gigantesca bolsa de dinero 'hay que ir por ella'”. Se trata de atraer al capitalino dándole el mejor servicio en la carretera.

Para esto formaron una cadena de servicios a partir del uso de productos regionales: tomate, calabazas, pollo, hortalizas, queso, frijol, maíz, entre otros. Por medio de préstamos a los productores agrícolas genera-

8 Se trata del restaurante Parador Cerro Gordo, cuyo titular tuvo la amabilidad de explicar, en el marco de la investigación, el modelo de negocios imperante y las principales ideas de este segmento. 
ron la reactivación de la economía local. Explicando mejor, se diría que más allá de colocarlos en un mercado incierto, sus consumidores son los visitantes de la ciudad de Xalapa que frecuentan los restaurantes de Cerro Gordo. Argumentan que junto a esta estrategia organizativa de la localidad se propusieron contrastar a la frialdad de las cadenas globales de restaurantes la calidez local. De esa manera, según el propietario del restaurante, "los pueblos podemos competir en el mundo globalizado con lo que sabemos hacer tradicionalmente, lo demás se irá puliendo”.

Al igual que en Rinconada existen problemas de inseguridad desde hace diez años, especialmente robos y otros actos delictivos. Como consecuencia de ello se creó una organización entre vecinos que se apoyan mutuamente. Para cerrar la posición ante la construcción de la autopista, la posición de la localidad de Cerro Gordo fue “dejar fluir” y, evitar que se generaran conflictos. Se consideran favorecidos, pues, aunque en el entronque de la autopista que ocupa Corral Falso se presenta más flujo vehicular, esta localidad no ha impulsado ningún emprendimiento para desarrollarse económicamente y aprovechar la posición privilegiada en la autopista.

\section{Observaciones finales}

La construcción de la autopista fue una decisión pública de orientación global. Sus impactos locales fueron diferenciados, así como las formas de reacción social ante la obra. Esto se puede encontrar en la configuración de subjetividades alrededor del proceso de reestructuración económico y espacial. Estas subjetividades que ubican a la acción social ante la obra no eran homogéneas en ninguno de los casos: Corral Falso, Rinconada y Cerro Gordo. Las localidades se definen porque una de las formas de reacción social fue hegemónica sobre las otras y se impuso como una corriente principal local. Aunque son tipo ideales —negociación judicializada, resistencia política y aceptación negociada - ninguna es pura. Son fuerzas en tensión donde la corriente principal de cada caso se presenta como una estructura de relaciones intra-locales y como posibilidad de 
enfrentamiento a la reestructuración de las economías locales, la reformulación de las fuerzas políticas y la reconfiguración del territorio.

En Corral Falso la corriente principal fue de "negociación”, utilizando instrumentos jurídicos y morales que generaron negociaciones exitosas, manteniendo la estructura del pueblo. La autopista fue aceptada y benefició al pueblo, pero como resultado de una lucha ante la imperatividad del proyecto. Funcionó la vía jurídica (CDDHAC) y no hubo disputa económica, pues la localidad no depende de las empresas locales, sino más bien de la generación de empleos en Xalapa.

En Rinconada la corriente principal fue de "resistencia" utilizando instrumentos políticos y sociales. El área estructural se ubica en el libramiento, lo que permite a los usuarios de la autopista optar entre atravesar el pueblo y hacer algún gasto en antojitos o mariscos de excelente sabor o la comodidad y rápidez del libramiento. A la fecha existe división política y social entre ganadores y perdedores. Los resultados fueron claros: afectación económica, incremento de la inseguridad, desaliento moral. Cabe mencionar que la autopista fue rechazada desde el primer momento.

En Cerro Gordo la corriente principal fue de “aceptación”, a partir de instrumentos de organización campesina y de recursos tradicionales que les permitió colocarse en la mejor posición y aprovechar los veinte minutos de cercanía a la capital xalapeña ("la gran bolsa de dinero"). El área estructural es evitada por el libramiento, mantiene una posición en entronque con una caseta de cobro que les favoreció mucho, pues supieron aprovechar su situación. Tuvieron éxito con un modelo de negocios que pretenden continuar, pues conlleva la generación de un pequeños clúster que aun cuando es limitado espacialmente, es eficiente en la generación de recursos propios.

En materia económica es válido precisar que en el caso de Corral Falso nunca estuvo en juego la sustentabilidad de la localidad, porque esta 
no depende del comercio carretero; en Rinconada la economía se concentró casi en un solo producto (la garnacha) lo cual no ha sido suficiente; Cerro Gordo no solo mostró flexibilidad ante los cambios, sino que supo aprovechar el cambio adaptándose a las nuevas demandas: agricultura, avicultura, comercio de alimentos y empleos en Xalapa, y con ello aseguró el éxito, además de que sus alimentos forman parte de una tradición que privilegia lo asado sobre lo frito.

La subjetividad religiosa ha sido muy importante para la organización social tanto en Corral Falso como en Cerro Gordo. Estas subjetividades aparecieron junto con la relevancia de las antiguas estructuras campesinas, particularmente la asamblea ejidal, en la acción social emprendida frente al imperativo de la autopista.

Por supuesto que la posición geográfica de Cerro Gordo sí lo favoreció, no todo es producto del acto subjetivo de los actores, pero además de las condiciones objetivas se dieron circunstancias subjetivas que fueron determinantes para su éxito.

En Rinconada el libramiento afectó estructuralmente a la localidad, pero también reventó relaciones políticas que estaban subyaciendo en situación de conflicto. Si antes de la construcción de la autopista Xalapa-Puerto de Veracruz era la localidad más favorecida y con mejor estructura de negocios (micro y pequeñas empresas) la pregunta es: ¿Qué cambió el rumbo del flujo del dinero que llegó a concentrarse en ese punto del municipio de Emiliano Zapata, Veracruz, durante treinta años? La respuesta es que se fracturó, se dividió por razón de una decisión gubernamental autoritaria que no tomó en ningún momento en cuenta ni los intereses ni las necesidades de los habitantes de las localidades ubicadas a orilla de la carretera. En síntesis, lo que pasó fue lo siguiente:

1. Las clases medias de Xalapa y turistas de paso optaron por favorecer a Cerro Gordo porque les representa ahorro de la caseta, comida diversa y 
$20 \mathrm{kms}$ de diferencia antes de Rinconada. Esto no implica que muchos desistan de ir hasta Rinconada, pero Cerro Gordo está más cerca de la capital xalapeña y en el libramiento de Rinconada no hay caseta de cobro para la autopista de cuatro carriles.

2. Los choferes de tráileres y camiones de carga optaron por favorecer a Tamarindo, en el municipio de Puente Nacional a mitad de camino entre la capital de Xalapa y el Puerto de Veracruz. Allí encuentran regaderas, comida, estimulantes para soportar las largas horas de camino, mujeres y diversión en las "cachimbas" o restaurantes carreteros donde se vende también cerveza. Obviamente allí no se detienen los paseantes de la clase media regional, como también es raro ver a traileros en Cerro Gordo.

Para el caso del municipio de Emiliano Zapata, Veracruz, la imposición de la construcción de la autopista Xalapa-Puerto de Veracruz (20012004) activó configuraciones subjetivas en sus habitantes, que llevaron a reacciones sociales de al menos tres tipos (negociación, aceptación y resistencia) en las localidades afectadas; sin embargo, las condiciones objetivas como el entramado de empresas (micro y pequeñas) también determinó que cada localidad sorteará el cambio de manera más o menos exitosa. De esta manera, los factores subjetivos y objetivos de la acción colectiva no pueden aislarse si se pretende una explicación plausible de los fenómenos sociales.

\section{Referencias}

Alemán, Miguel. (2004). 6to Informe de Gobierno 2003-2004. Recuperado el 8 de abril de 2015 de http://www.alemanvelasco.org/Inf\%20Veracruz/ Informe.pdf

AVC Noticias. (2015) "Cae 70\% la actividad comercial en Rinconada. El libramiento de Rinconada afectó la economía de la zona”. Recuperado el 12 de mayo de 2020 de http://www.oyeveracruz.com.mx/resumen. php?id $=45943$

Baez-Camargo, Claudia y Ledeneva, Alena. (2017). Where Does Informality Stop and Corruption Begin? Informal Governance and the Public/Private 
Crossover in Mexico, Russia and Tanzania. Slavonic and East European Review, 95(1), 49-75.

Bueno, Carmen y Margarita Pérez. (2006). Introducción. Espacios globales, espacios socialmente construidos. En Carmen Bueno y Margarita Pérez (Coords.), Espacios globales (pp. 9-19). México: Universidad Iberoamericana/Plaza y Valdés.

Cuervo, Luis Mauricio. (2003). Ciudad y globalización en América Latina: estado del arte. Santiago de Chile: Comisión Económica para América Latina y el Caribe.

Chignola, Sandro y Mezzadra, Sandro. (2014). Fuera de la política pura: Laboratorios globales de la subjetividad. Política común, 6. Recuperado de quod.lib: https://quod.lib.umich.edu/p/pc/12322227.0006.005? view = tex t;rgn = main

Flores, Carlos. (2017). Actores de poder, instituciones y tráficos de drogas en Tamaulipas: 1964-1988. En Gilberto Giménez y René Jiménez (Coords.), La violencia en México a la luz de las ciencias sociales (pp. 135-186). México: Universidad Nacional Autónoma de México.

Garza, Enrique de la (2018). Metodología configuracionista para la investigación. México: Editorial Gedisa/Universidad Autónoma Metropolitana.

Hevia, Felipe y Vergara-Lope, Samana. (2011) ¿Cómo medir la participación? Creación, validación y aplicación del Cuestionario Conductas de Participación. México: Centro de Investigación y Estudios Superiores en Antropología Social/Instituto Nacional de Desarrollo Social.

Hinkelammert, Franz. (2001). El nihilismo al desnudo. Los tiempos de la globalización. Santiago de Chile: LOM-Ediciones.

Merino, Mauricio. (2013). Políticas públicas. Ensayo sobre la intervención del Estado en la solución de problemas públicos. México: Centro de Investigación y Docencia Económicas.

Moreno, Saúl. (2016). El impacto local de la construcción de la autopista Xalapa-Veracruz. El caso de Rinconada, Veracruz. En Petra Armenta y Arturo Durán (Coords.), Globalidad, federalismo y vida local. Paradojas y tendencias (pp. 202-221). Xalapa: Universidad Veracruzana. 
Moreno, Saúl. (2017). Obstáculos político culturales para la buena gobernanza. El caso de la reacción social ante la construcción de la autopista VeracruzXalapa en Rinconada, Veracruz. En Ady Carrera (Coord.), El municipio ante la crisis del federalismo mexicano (pp. 39-52). México: Red Nacional de Investigadores en Gobiernos Locales Mexicanos.

Muñoz Espejo, Francisco. (s.f.). Camino real de Veracruz-México. Por las veredas de la historia. En Patrimonio Cultural y Turismo. Cuadernos. 15. Itinerarios culturales y rutas del patrimonio. Ciudad de México: Conaculta.

Olvera, Alberto. (2018). Gestación y crisis del régimen político electoral autoritario en Veracruz. En Alberto Olvera (Coord.), Veracruz en su laberinto. Autoritarismo, crisis de régimen y violencia en el sexenio de Javier Duarte (pp. 23-51). Xalapa: Universidad Veracruzana.

Orizaba en Red. (2004) Gustavo Nachón Aguirre, expresó que Veracruz es la entidad más y mejor comunicada. Orizaba en Red, s/p, online, México.

Ortiz, Sofia. (2010) Modernización y ampliación del puerto de Veracruz y su impacto en la economía mexicana. Revista Exploratoris. Observatorio de la Realidad Global, Vol.1, s/p, online, México.

Porto-Gonçalves, Carlos Walter. (2009). De Saberes y de Territorios - diversidad y emancipación a partir de la experiencia latinoamericana. Polis. Revista Latinoamericana, (22), 1-13. Recuperada de journals: https://journals. openedition.org/polis/2636?lang = pt

Sánchez, Juan José. (2002). La globalización al desnudo. Un viaje desde la realidad económica y tecnológica hasta la intimidad del corazón humano. Barcelona: Chaos-Entropy.

Sassen, Saskia. (2010). Territorio, autoridad y derechos. De los ensamblajes medievales a los ensamblajes globales, Buenos Aires: Katz Editores.

Zavaleta, Alfredo. (2018). Desapariciones, violencia organizada y colectivos de víctimas en México. El caso de la región Golfo/Sureste. En Alberto Olvera (Coord.), Veracruz en su laberinto. Autoritarismo, crisis de régimen y violencia en el sexenio de Javier Duarte (pp. 273-279). Xalapa: Universidad Veracruzana. 